(Aus der Dermatologischen Klinik der Universität Breslau [Direktor: Geheimrat Prof. Dr. Jadassohn].)

\title{
Ủber die Achorion-Quinckeanum-Erkrankung der graviden Meerschweinchen und über das Verhalten ihrer Nachkommen zur Allergie.
}

\author{
Von
}

\author{
Dr. med. Hans Martenstein,
}

Assistenzarzt der Klinik.

(Eingegangen am 17. Februar 1922.)

Im Verlaufe einer der zahlreichen Impfserien mit Achorion Quinckeanum an Meerschweinchen, die zu anderen $Z$ wecken vorgenommen wurden, fiel mir bei einem Tier der eigenartige Verlauf der Krankheit auf, da gerade diese Infektion, mit ganz geringfügigen Abweichungen an Dauer und Intensität, bei allen Tieren außerordentlich gleichmäßig verläuft. Das erwähnte Tier war gravid. Der Ablauf der Infektion mit Achorion Q. bei diesem Tier näherte sich sehr dem bei der Zweitimpfung eines Meerschweinchens mit diesem Pilz, wie das im folgenden näher beschriebene Krankheitsbild erkennen läßt. Es schien, als ob die Abwehrkräfte des normalen Organismus durch die Schwangerschaft eine Änderung erführen. Um einen Zufallsbefund auszuschließen, wurden vier weitere gravide Tiere einer Impfung mit Achorion Q. unterzogen. Der Krankheitsablauf war, von geringfügigen Abweichungen abgesehen, bei allen fünf Tieren so übereinstimmend, daß die Wiedergabe eines Protokolls genügt:

11. VIII. 1921. Meerschweinchen in gravidem Zustand wird mit einer etwa 10 Wochen alten Kultur von Achorion Quinckeanum in der üblichen Weise am Rücken links geimpft.

12. VIII. Traumatische Reaktion.

13. VIII. Traumatische Reaktion schwächer.

14. VIII. Erythem. Angedeutete Schuppenbildung.

15. VIII. Deutliche Schuppenbildung. Beginnende Infiltration.

16. VIII. Deutliche, aber nicht sehr starke Infiltration, Zentrum zeigt schwache Borkenbildung, Randzone Schuppung.

17. VIII. Randzone vergrößert sich.

18. VIII. Erythem, Infiltration und Schuppenbildung in gleicher Stärke. Der Krankheitsherd umfaßt heute etwa das Doppelte des geimpften Hautbezirkes. Der ganze Krankheitsprozeß zeigt nicht den gewöhnlichen akuten Verlauf, sondern macht mehr den Eindruck eines subakut oder chronisch verlaufenden Leidens. 
330 H. Martenstein: Über die Achorion-Quinckeanun-Erkrankung der graviden

20. VIII. Schuppenbildung am Rand gesteigert.

21. VIII. Das Zentrum fängt an, einen Rückgang der Krankheitserscheinungen zu zeigen.

23. VIII. Krankheitsherd fünfmarkgroß, im Zentrum ist ein etwa eine Mark großer Bezirk fast ganz abgeheilt, während die Randzone deutliche Infiltration und etwas geringere Schuppenbildung als vorher zeigt.

25. VIII. Infiltration am Randteil abklingend, Schuppenbildung noch vorhanden.

28. VIII. Impfherd narbenähnlich abgeheilt.

Die Daten für die Inkubationszeit, Beginn der zentralen Abheilung und Krankheitsdauer sind für die einzelnen Tiere, Tier I: Inkubation 3 Tage? (Wie in allen anderen Fällen unmerklicher Übergang aus traumatischer Reaktion in Krankheitserscheinungen), Beginn der zentralen Abheilung nach 11 Tagen, Gesamtkrankheitsdauer 15 Tage.

Tier II: 2-3 Tage? Nach 10 Tagen, 17 Tage.

Tier III: 2-3 Tage? Nach 7 Tagen, 16 Tage.

Tier IV: 3 Tage? Nach 10 Tagen 17 Tage.

Tier V: 2-3 Tage? Nach 11 Tagen, 16 Tage.

Ergebnis: Die Erstimpfung von vier graviden Meerschweinchen bestätigt die an einem graviden Tier vorher gemachte Beobachtung, daß

1. keine scharf abgegrenzte Inkubationszeit besteht. Diese erscheint verkürzt, die traumatische Reaktion der Impfung geht in den Krankheitsprozeß ohne deutliche Grenze über. Normale Inkubationszeit: 4-5 Tage.

2. Der Krankheitsverlauf weicht von der bekannten Form erheblich $a b$. Die einzelnen Stadien treten nicht markant hervor. Es kommt nicht zum plötzlichen starken Anschwellen der Krankheitssymptome, es fehlt die massige Scutulabildung und ihre ziemlich rasche Abstoßung im ganzen. Der Krankheitsprozeß verläuft mehr subakut, zeigt ziemlich bald im Zentrum auftretende narbenartige Abheilung, die nach dem Rande zu fortschreitet.

3. Die ganze Krankheitsdauer ist deutlich verkürzt auf 15-17 Tage gegen 20-21 Tage bei normalem Verlauf.

Da die Schwangerschaftsdauer beim Meerschweinchen ziemlich konstant 72 Tage beträgt, läßt sich nach dem Zeitpunkt des Wurfes (Tier I: 2 am 27. VII. 1921, Tier II: 2 am 18. VII. 1921, Tier III: am 18. VIII. 1921, Tier IV: 2 am 15. VIII. 1921, Tier V: 3 am 26. VIII. 1921) errechnen, daB die Schwangerschaftsdauer der Tiere am Tage der Impfung bei I 58 Tage, bei II und III 65 Tage, bei IV 68 Tage und bei V 57 Tage etwa betrug. Sämtliche Tiere befanden sich also am Ende der Gravidität.

Nach dem Verlauf der Achorion-Quinckeanum-Infektion bei den fünf untersuchten graviden Meerschweinchen muß man annehmen, daß sich ihr Organismus der Infektion gegenüber anders verhält, als der eines nicht geschwängerten, normalen Tieres. Und da die Krankheit sowohl an Dauer, als auch an Intensität vermindert erscheint, muß man annehmen, daß dieser Verlauf durch eine Änderung der im normalen Organismus vorhandenen Abwehrkräfte bedingt ist. 
Daß akute und chronische Infektionskrankheiten bei schwangeren Individuen einen von der Norm abweichenden Verlauf nehmen können, ist bekannt. Dieser ist im allgemeinen schwerer und die Prognose besonders in den letzten Monaten der Gravidität ungünstig [Bumm $\left.{ }^{1}\right)$, was vor allem auf die herabgesetzte Widerstandskraft der Atmungsorgane und des Urogenitalapparates zurückgeführt wird. Aber die Beeinflussung von Krankheiten, die vor oder während der Schwangerschaft entstanden sind, durch diese geht durchaus nicht immer in derselben Richtung und ist nicht einmal bei der gleichen Krankheit stets gleichsinnig.

Jadassohn ${ }^{2}$ ) erwähnt, daß die Gravidität bei dem einen Individuum die Disposition zur Psoriasiserkrankung erhöhen, bei dem anderen herabsetzen, die Psoriasis im ungünstigen, bzw. im günstigen Sinn beeinflussen kann. Tommasoli ${ }^{3}$ ) bat einen Fall beobachtet, in dem 11 mal hintereinander bei jeder Schwangerschaft ein Psoriasisrezidiv eingetreten ist. Ferner sah er eine Psoriasis während der Gravidität verschwinden; Rossi ${ }^{3}$ ) sah eine Psoriasis, die während der Schwangerschaft auftrat, nach einem künstlichen Abort abheilen. In seiner Monographie, der auch die vorstehenden Angaben entnommen sind, führt Marcuse $^{3}$ ) noch eine Reihe anderer Beobachtungen über diese Frage an. So kann der Lupus vulgaris beim Eintritt einer Gravidität stationär bleiben, verschlimmert oder auch geb ssert werden (Bar, Jadassohn, Thibierge). Auch bei mehreren anderen Hautkrankheiten ist manchmal der Einfluß der Schwangerschaft auf ihren Verlauf festgestellt worden, z. B. bei Ekzem, Lupus. erythematodes usw.

H. Freund ${ }^{4}$ ) hat die Erfahrung gemacht, daß bei Graviden sehr häufig ein Dermographismus besteht, was bei normalen Frauen für gewöhnlich nicht der Fall ist. Die Reaktion der Capillaren auf mechanische Reize bei Nichtschwangeren, Schwangeren und Wöchnerinnen ist in neuester Zeit von Lennartz ${ }^{5}$ ) mit dem Leitzschen Binokularmikroskop untersucht worden; bei Schwangeren bestehen häufig Stasen, die Capillaren zeigen längere Schlingen mit erweitertem venösen Schenkel. Bei Schwangeren bewirken mechanische Reize die stärksten Veränderungen: hellrote Farbe und schnellste Strömung an Stellen, an denen vorher blaurote Farbe und langsame Strömung bis zur Stase bestand. Interessante Versuchsergebnisse über intracutane Impfungen von endokrinen Organextrakten hat o. Gans ${ }^{6}$ ) mitgeteilt. Ich erwähne hier nur die mit und an Graviden in den letzten Wochen vor dem Partus erzielten Ergebnisse.

Wässerige und alkoholische Organextrakte verursachen bei Graviden den weitaus schwächsten Reaktionsverlauf (schwächer als; bei nicht schwangeren Frauen, bei diesen schwächer als bei Männern).

2. Organextrakt + Plasmagemenge erzeugt eine Reaktion, die sich im Erythem bei Männern, Frauen und Graviden nicht unterscheidet, wohl aber in der. Infiltration, die in der genannten Reihenfolge abnimmt.

1) Bumm, Lehrbuch der Geburtshilfe.

2) Jadassohn, Psoriasis und verwandte Krankheiten. Med. Klinik 1915, Nr. 39 und 40.

3) Marcuse, Max, Hautkrankheiten und Sexualität. Separatabdruck der Wiener Klinik 1906, S. 50. S. 409.

$\left.{ }^{4}\right)$ H. Freund, VI. Kongreß der Deutschen Derm. Gesellschaft, Straßburg 1898;

5) Lennartz, Pflügers Arch. f. d. ges. Physiol. 191, 302. 1921.

6) O. Gans, Dermatol. Wochenschr. 1921, S. 841. 
3. Organextrakt + Graviden-Plasmagemenge liefert dieselben Ergebnisse wie bei 2.

4. Organextrakt + Graviden-Serum ruft bei Graviden eine Reaktion hervor, die sowohl an Intensität, als auch an Dauer des Erythems und Infiltrats die Reaktion bei nicht schwangeren Frauen und erst recht die bei Männern übertrifft.

Diese Befunde zeigen die veränderte Reaktionsfähigkeit der Haut; daneben seien noch kurz einige Mitteilungen über Änderungen in der Beschaffenheit des Blutes angeführt. Neu${ }^{1}$ ) konnte nachweisen, daß bei Schwangeren der Gehalt an adrenalinähnlichen Substanzen im Blute stark vermehrt ist, Sachs und v. Oettin$g^{2}{ }^{2}$ ), daß das Blutplasma von Graviden besonders labil (der Neugeborenen besonders stabil) ist und eine geringere Oberflächenspannung besitzt. Diese Autoren sprechen die Vermuiung aus, daß das Vorhandensein von Antikörpern im Blute im wesentlichen Maße von seiner physikalischen Struktur abhängig ist, und führen das Fehlen von Antikörpern beim Neugeborenen auf die erhöhte Oberflächenspannung des Blutplasmas zurück. SchlieBlich teilt Pfeiler ${ }^{3}$ ) folgenden Fall mit: „Eine gegen Rotz immunisierte, aber niemals mit lebenden Rotzbacillen in Berührung gekommene Stute zeigte, nachdem das Blutbild wieder negativ geworden war, beim Rossigsein, bzw. bei Trächtigkeit einen positiven Blutbefund. Pfeiler nimmt eine Allergie an, die durch nicht spezifische physiologische Vorgänge wachgerufen worden ist.

Ich habe diese Beobachtungen zwanglos und ohne etwa Anspruch auf Vollständigkeit erheben zu wollen, angeführt, um zu zeigen, welche eingreifende Veränderungen in den Funktionen des Gesamtorganismus und - was ja längst bekannt ist - besonders in der Haut (Pigment!) durch die Schwangerschaft hervorgerufen werden, und daB Analogien zu den von mir gefundenen Vorgängen bestehen. Am deutlichsten kommt die Analogie mit meinen Untersuchungsergebnissen in den Befunden von Brown und Pearce ${ }^{4}$ ) zum Ausdruck. Diese haben gefunden, daß weibliche Kaninchen während der Gravidität eine natürliche Immunität gegen den Erreger der Syphilis besitzen. Bei normalen Kaninchen bekommt man als Folge der Infektion mit Pallidae fast konstant eine chancriforme Läsion mit regionärer Drüsenschwellung, bei graviden entsteht oft keine Läsion. Bei vier infizierten graviden Tieren erzielten die Autoren in zwei Fällen ein vollkommen negatives Ergebnis, in einem Allgemeinerscheinungen ohne eine Hautläsion und nur in einem eine typische Primärläsion an der Infektionsstelle.

\section{II.}

Es lag nahe zu untersuchen, ob die Nachkommen der während der Schwangerschaft einer Infektion mit Achorion Quinckeanum ausgesetzten Meerschweinchen im Verhalten ihrer Epidermis und ihres Blutserums gegenüber Achorion Quinckeanum Eigenschaften aufwiesen, die im Sinne einer Allergie zu deuten wären. Über die Technik der Untersuchung siehe meine Mitteilung im Arch. f. Dermatol. 1. Syphilis, Bd. 131.

1) Neu, Münch. med. Wochenschr. 1910, Nr. 48 und 1911, Nr. 34.

2) Sachs und v. Oettingen, Münch. med. Wochenschr. 1921, Nr. 12.

3) Pfeiler, Zentralbl. f. Bakteriol. usw., Abt. II. 85, H. 6/7.

4) Brown und Pearce, Americ. journ. of syphilis 10,593. 1920. 


\section{Protokoll.}

Es werden Epidermis und Serum der am 27. VII. 1921 geworfenen 2 Jungen (Tier I) auf ihren Gehalt an dem spezifischen Körper untersucht, der mit Sporen von Achorion Q. die spezifische toxische Substanz bildet. Ebenso werden 2 Junge rom Tier IV, am 15. VIII. 1921 geworfen, untersucht. Das Material von den. 2 ersten Jungtieren wird am 7. XII. 1921 entnommen, also 133 Tage nach der Geburt, von den anderen beiden am 8. XII. 1921, also 115 Tage post partum. Als Kontrolle werden Epidermis und Serum eines normalen Tieres geprüft.

Untersucht werden nach der oben genannten Methode: Epidermis-Extrakt

Serum Epidermis + Achor.-Q.-Extr. aller 5 Tiere. Serum + Achor.-Q.-Extrakt.

Die am 8. XII. 1921 bzw. am 9. XII. 1921 vorgenommenen intradermalen Einspritzungen von $0,1 \mathrm{ccm}$ der zu untersuchenden Extrakte in die Rückenhaut von normalen Meerschweinchen ergeben durchweg ein negatives Resultat: Extrakte aus Epidermis und Epidermis + Achor. Q. vollkommen negativ, Extrakte aus Serum und Serum + Achorion Q. ganz schwache und kurzfristige Reaktionen wie sie die früheren zahlreichen Versuche immer ergeben haben.

Jedenfalls verhalten die etwa vier Monate alten Jungen von Meerschweinchen, die während ihrer Gravidität eine Infektion mit Achorion $Q$. durchgemacht haben, sich nicht anders als ein normales Tier.

Da sich in der Zeit von vier Monaten nach der Geburt immerhin die Tiere in bezug auf ihre Allergie gegenüber Achorion Q. geändert haben könnten, werden, da die Tiere I, II und IV am 16. XII. 1921 bzw. am 15. XII. wieder 2, bzw. 2, bzw. 3 Junge geworfen haben, 2 von diesen Jungen 3 bzw. 4 Tage nach der Geburt ebenfalls auf das Verhalten der Epidermis und des Serums gegenüber Achorion Q. untersucht. Gleichzeitig wird geprüft, ob das Niuttertier IV noch den spezifischen Stoff in seiner Epidermis und seinem Serum enthält (130 Tage nach der Impfung). Die intradermalen Einspritzungen von 0,1 ccm der Extrakte von Epidermis der Jungen, Epidermis + Achorion Q., Serum und Serum + Achorion Q., der gleichen Tiere in die Rückenhaut eines normalen Tieres (entnommen am 19. XII. 1921, eingespritzt am 20. XII. 1921) ergeben, daß der spezifische Stoff auch kurz nach der Geburt weder in der Epidermis, noch im Serum der Jungen einer mit Achorion $Q$. infiziert gewesenen Mutter nachauweisen ist.

Im Muttertier ist dieser Stoff bei gleichzeitiger Untersuchung in Epidermis und Serum sicher vorhanden.

Um zu prüfen, ob sich dieser Befund bestätigt, werden die Jungen vom Muttertier I und vom Muttertier IV (siehe oben) und ein normales Tier mit einer etwa 10 Wochen alten Kultur von Achorion Q. in der gewöhnlichen Weise am Rücken geimpft. Impfung am 10. XII. 1921. Inkubation: 5 Tage. Gesamtkrankheitsdauer, von der Impfung ab gerechnet: $20-21$ Tage. Und zwar gelten diese Daten für alle fünf Tiere, es besteht also kein Unterschied im Verhalten des normalen 
Tieres und der Jungen einer mit Achorion Q. infiziert gewesenen Mutter gegenüber einer Impfung mit diesem Pilz.

Ergebnis: Die vom Muttertier durch das Überstehen einer Achorion Quinckeanum-Intektion erworbene Allergie wird nicht auf seine Nachkommen iibertragen.

Dieses Ergebnis war nicht von vornherein zu erwarten. „Die Immunität, die ein weibliches Tier während der Schwangerschaft durch das Überstehen einer Infektionskrankheit - ich folge den Ausführungen Rosenthals ${ }^{1}$ ) - oder durch künstliche Immunisierung erwirbt, wird häufig in mehr oder minder hohem Grade auf die Neugeborenen übertragen." Manchmal kann man in ihrem Blute auch Antikörper nachweisen. Der Antikörpergehalt ist bei den Kindern meistens geringer als bei der Mutter. In der weitaus größten Zahl der Fälle, in denen bei den Kindern Antikörper nachzuweisen sind, ist die Mutter während der Gravidität infiziert worden. Die beim Neugeborenen nachweisbaren Antikörper verschwinden bald aus seinem Blut. Sie bleiben bei manchen Tierarten länger nachweisbar, wenn die Jungen von der Mutter gesäugt werden. Die Milch solcher Tiere enthält nachweisbare Antikörper und bewirkt passive Immunisierung bei einzelnen Tierarten. Bei Meerschweinchen gelingt diese nicht (Ehrlich).

Bei unseren Versuchen wurden Tiere untersucht, die zur Zeit der mütterlichen Infektion Föten waren, und Jungen, die lange nach Ablauf der mütterlichen. Krankheit gezeugt und ausgetragen wurden. In der Epidermis der Muttertiere sind Antikörper in Epidermis und Serum des Blutes sicher nachgewiesen. Wie ich in anderen Versuchen zeigen konnte, sind die Antikörper im mit Achorion Q. infizierten Tier im Serum 7 Tage nach der Infektion, in der Epidermis 8-9 Tage p.i. festzustellen. Zwei der untersuchten Jungen wurden 14 Tage nach der Infektion der Mutter, zwei 4 Tage p. i. geworfen. Bei diesen käme also nur eine aktive Immunisierung in Frage, bei den ersterwähnten sowohl eine aktive, als auch eine passive. Daß die Untersuchungen ein durchaus negatives Ergebnis hatten, könnte nach dem oben Gesagten daran liegen, da $B$ die Jungen erst im Alter von etwa 4 Monaten untersucht wurden. Aber auch die 3 bzw, 4 Tage nach der Geburt untersuchten Jungen einer Mutter, bei der noch sicher Antikörper in Epidermis und Blutserum vorhanden sind, zeigen keine Überempfindlichkeitserscheinungen. Man darf danach wohl annehmen, und die Ergebnisse Ehrtichs deuten schon darauf hin, daß das Meerschwein zu den Tierarten gehört, bei denen vom infizierten Muttertier keine oder keine nachweisbaren Mengen von Antikörpern auf die Nachkömmlinge übergehen. Übrigens hat Sutter ${ }^{2}$ ) bei seinen Untersuchungen über die Reak-

1) Werner Rosenthal, Tierische Immunität. Braunschweig 1914. Bd. 53 der „Wissenschaft".

$\left.{ }^{2}\right)$ Sutter, Arch. f. Dermatol. u. Syphilis, Orig. 24, 65. 
Meerschweinchen und über das Verhaiten ihrer Nachkommen zur Allergie. 335

tionsfähigkeit von Gesunden auf Trichophytin u. a. gefunden, daß von 12 untersuchten Säuglingen 11 negativ, 1 schwach positiv reagierten, während von 11 Kindern im Alter von 1 -3 Jahren nur 4 negativ, 7 schwach positiv und von 17 Kindern zwischen 3 and 15 Jahren 2 negativ, 8 schwach positiv und 7 mittelstark positiv reagierten. Sutter faßt die positive Trichophytinreaktion bei Gesunden als allgemeine Antigenreaktion auf. Analogisiert man Sutters Versuchsergebnisse mit den meinen, so kann man sich vorstellen, daß das neugeborene Meerschweinchen auch zu einer spezifischen Antigenreaktion nicht fähig ist, vorausgesetzt, daß vom Muttertier Antikörper auf das Jungtier, wenn auch nicht in nachweisbarer Menge, übergehen.

\section{Zusammenfassung.}

1. Die Erstimpfung mit Achorion Quinckeanum an fünf graviden Meerschweinchen ergibt, daß keine scharf abgegrenzte Inkubationszeit besteht, der Krankheitsverlauf mehr subakut erscheint (geringere Intensität der Entzündung und der Scutulabildung, zentrale Abheilung) und die Gesamtkrankheitsdauer deutlich verkürzt ist.

2. Die vom Muttertier durch diese Infektion erworbene Allergie wird nicht auf seine Nachkommen übertragen. 